\title{
A Longitudinal Analysis of the Mortality Spectrum of Children under 5 Years from 1990 to 2015 in Hubei Province of China
}

\author{
Zhonggui Xiong ${ }^{1}$, Yusong $\mathrm{Xu}^{1}$, Xiangdong $\mathrm{Li}^{2} \&$ Junxin $\mathrm{Shi}^{3}$ \\ ${ }^{1}$ Department of Child Health, Hubei Maternal and Child Health Hospital, Wuhan, China \\ ${ }^{2}$ Department of Maternal and Child Health, Hubei Health and Family Planning Committee, Wuhan, China \\ ${ }^{3}$ Center for Injury Research and Policy, The Research Institute at Nationwide Children's Hospital, Columbus, \\ USA \\ Correspondence: Zhonggui Xiong, Department of Child Health, Hubei Maternal and Child Health Hospital, \\ Wuhan, 430070, P. R. of China. Tel: 86-27-8786-9844(O). Fax: 86-27-8788-4730.
}

Received: June 10, 2017 Accepted: July 12, 2017 Online Published: July 25, 2017

doi:10.5539/gjhs.v9n9p138 URL: https://doi.org/10.5539/gjhs.v9n9p138

This research was funded by Hubei Health and Family Planning Committee of China. The funders had no role in research design, data collection, statistical analysis or publication.

\begin{abstract}
Objectives: This research analyzed trends of the mortality spectrum resulted from dynamics of the health care service for children under 5 years.

Methods: It was sampled 23 surveillance sites to establish a population-based surveillance network for children under 5 years by implementing a multistage randomized, stratified and cluster sampling since 1990 in Hubei province of China.

Results: Among children under 5 years, the mortality rates of pneumonia, birth asphyxia, preterm birth/low birth weight and accidental asphyxia declined from $12.9,6.6,4.3$ and 3.5 in 1990 to $0.9,0.7,1.1$ and 0.7 per 1,000 live births in 2015 respectively, and manifested a distinguished milestone at which pneumonia and birth asphyxia had been replaced by preterm birth/low birth weight after $2005(\mathrm{P}<0.05)$. The death proportions of pneumonia and birth asphyxia decreased from $22.2 \%$ and $11.4 \%$ in 1990 to $10.3 \%$ and $7.7 \%$ in 2015 , while the death proportions of preterm birth/low birth weight and accidental asphyxia increased from $7.4 \%$ and $6.0 \%$ in 1990 to $12.9 \%$ and $8.6 \%$ in 2015 accordingly. The proportions of clinical diagnosis, emergence treatment and death place at the county/district hospitals increased from $9.0 \%, 27.4 \%$ and $28.7 \%$ in 1990 to $75.5 \%, 67.7 \%$ and $60.4 \%$ in 2015 , and had the significant differences between 1990 and 2015 in Hubei province $(\mathrm{P}<0.01)$.
\end{abstract}

Conclusions: It was suggested that the trends of the mortality spectrum were mainly due to the improvement of the health care service for children under 5 years in Hubei province.

Keywords: mortality spectrum; mortality rates; health care service

\section{Introduction}

Since child health and wellbeing continued to be one of the internationally recognized health challenges, the government of China formulated the National Program of Action for Child Development in which under-5-mortality rate $\left(\mathrm{U}_{5} \mathrm{MR}\right)$ decreased one-third from 1990 to 2000, one-fifth from 2000 to 2010 respectively. Furthermore, the United Nations proposed the Millennium Development Goal 4 (MDG4) in which $\mathrm{U}_{5} \mathrm{MR}$ reduced two-thirds from 1990 to 2015 (Julie, Linda, Alan, \& Christopher, 2010; Robert et al., 2010; You, Wardlaw, Salama, \& Jones, 2010).

However, there have been rare longitudinal reports on the mortality spectrum of the primary death causes for children under 5 years during a 25 -year period in many countries. The government of China established a nationwide surveillance network in 1990 to monitor the mortality rates of the primary death causes for children under 5 years (Wang et al., 2011). Therefore, it possessed the considerable application value, and provided the precious history data on child health and development in China. 
This research was aimed to analyze the trends of the mortality spectrum of the major death causes, to provide the scientific basis for the government at all levels to develop the necessary policies of maternal and child health in Hubei province.

\section{Methods}

\subsection{Surveillance Network}

Hubei province is situated in the central region of China, and flowed through by the Yangtze River which is the third longest one around the world. In this research, it has been sampled 23 surveillance sites (1 metropolis, 4 middle cities and 18 counties) to establish a population-based surveillance network for children under 5 years by implementing a multistage randomized, stratified and cluster sampling since 1990. This network had a large surveillance population of 4 millions who was in accordance with the demographic and geographic features in Hubei province of China.

All live births are defined as fetuses born more than 28 gestational weeks or 1,000 gram birth weight with at least one of the following vital signs: heartbeat, breathing, pulsation of umbilical cord or contraction of voluntary muscle. All mortalities of children under 5 years are classified as children dying from live birth to their fifth birthday. In this research, all information about live births and child mortalities were from their mothers who have been permanent residents, or who have lived in the surveillance areas for more than one year. Meanwhile, all live births and child mortalities were identified by the trained and licensed professionals of Hubei Maternal and Child Health Hospital (HMCHH).

\subsection{Death Classification}

The mortality code for children under 5 years was classified into 34 categories of the major death causes in accordance with the International Classification of Diseases, tenth edition (ICD-10), for example pneumonia, birth asphyxia, preterm birth/low birth weight, accidental asphyxia and the other death causes.

\subsection{Data Collection}

Based on an organization with three vertical levels of the surveillance system, the surveillance data were collected and reported by the trained and licensed health providers from 1990 across Hubei province. For child deaths inside the hospitals, the related information was collected via medical chart review. For child deaths outside the hospitals, the related information was collected via household visit. All data were then finally reported to $\mathrm{HMCHH}$ as the final data review of the surveillance system in Hubei province.

\subsection{Quality Control}

Quality inspection was conducted once quarterly in all the towns/streets by a sampling ratio of $100 \%$, twice annually in all the counties/districts by a sampling ratio of $25 \%$, and once annually across Hubei province by a sampling ratio of $10 \%$ based on the population framework. The error rates of the death diagnosis and questionnaire items were less than $5 \%$ and $1 \%$, and the missing rates of the mortality and live birth reports were no more than $15 \%$ and $10 \%$ respectively. This research was approved by the Ethics Committee of HMCHH. Written informed consents were obtained from all the parents or guardians of children under 5 years.

\subsection{Statistical Analysis}

The database was managed with Visual FoxPro (VFP 6.0), and the data were analyzed by Statistical Analysis System (SAS 8.1). Chi-square test was utilized to examine the differences in the mortality rates and health care service for children under 5 years between 1990 and 2015, and $\mathrm{P}$ value $<0.05$ was considered as the statistical significance.

\section{Results}

\subsection{Mortality Spectrum of the Primary Death Causes}

$\mathrm{U}_{5} \mathrm{MR}$ gradually declined from 58.1 in 1990 to 8.7 per 1,000 live births in 2015, and showed the dramatic decrease over the past 25 years in Hubei province $\left(\chi^{2}=94.88, \mathrm{P}<0.01\right)$. As for Hubei province, $\mathrm{U}_{5} \mathrm{MR}$ was at the average level from 1990 to 2015 in China.

Among children under 5 years, the mortality rates of pneumonia, birth asphyxia, preterm birth/low birth weight and accidental asphyxia decreased from 12.9, 6.6, 4.3 and 3.5 in 1990 to 0.9, 0.7, 1.1 and 0.7 per 1,000 live births in 2015 respectively. This research manifested a distinguished milestone at which the mortality rates of pneumonia and birth asphyxia had been replaced by that of preterm birth/low birth weight after 2005 in Hubei province $(\mathrm{P}<0.05)$ as shown in Figure 1. 


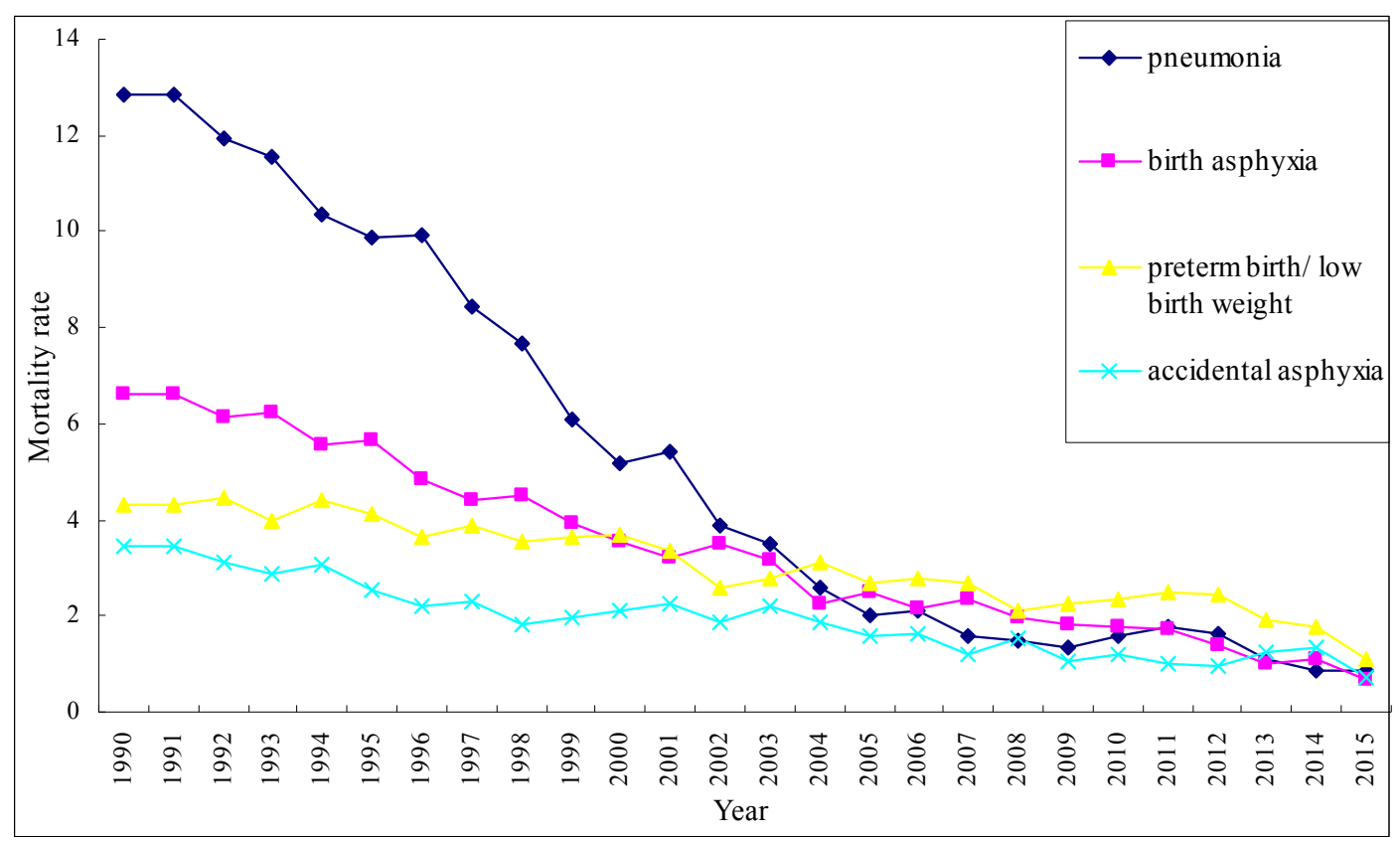

Figure 1. Mortality rates of the primary death causes for children under 5 years between 1990 and 2015 in Hubei province of China (per 1,000 live births)

Primary death causes: pneumonia $\left(\chi^{2}=142.91, \mathrm{P}<0.01\right)$, birth asphyxia $\left(\chi^{2}=35.68, \mathrm{P}<0.01\right)$, preterm birth $/$ low birth weight $\left(\chi^{2}=5.82, \mathrm{P}<0.05\right)$ and accidental asphyxia $\left(\chi^{2}=6.37, \mathrm{P}<0.05\right)$. Chi-square test: significant differences between 1990 and 2015.

\subsection{Death Proportions of the Primary Death Causes}

The death proportions of the primary death causes for children under 5 years accounted for $47.0 \%$ in 1990 and $39.5 \%$ in 2015 respectively, and had a significant reduction from 1990 to 2015 in Hubei province.

Among children under 5 years, the death proportions of pneumonia and birth asphyxia decreased from $22.2 \%$ and $11.4 \%$ in 1990 to $10.3 \%$ and $7.7 \%$ in 2015 , while the death proportions of preterm birth/low birth weight and accidental asphyxia increased from $7.4 \%$ and $6.0 \%$ in 1990 to $12.9 \%$ and $8.6 \%$ in 2015 accordingly. This research also displayed the dynamic trends in which the death proportions of pneumonia and birth asphyxia were gradually replaced by that of preterm birth/low birth weight from 1990 to 2015 as shown in Figure 2 . 


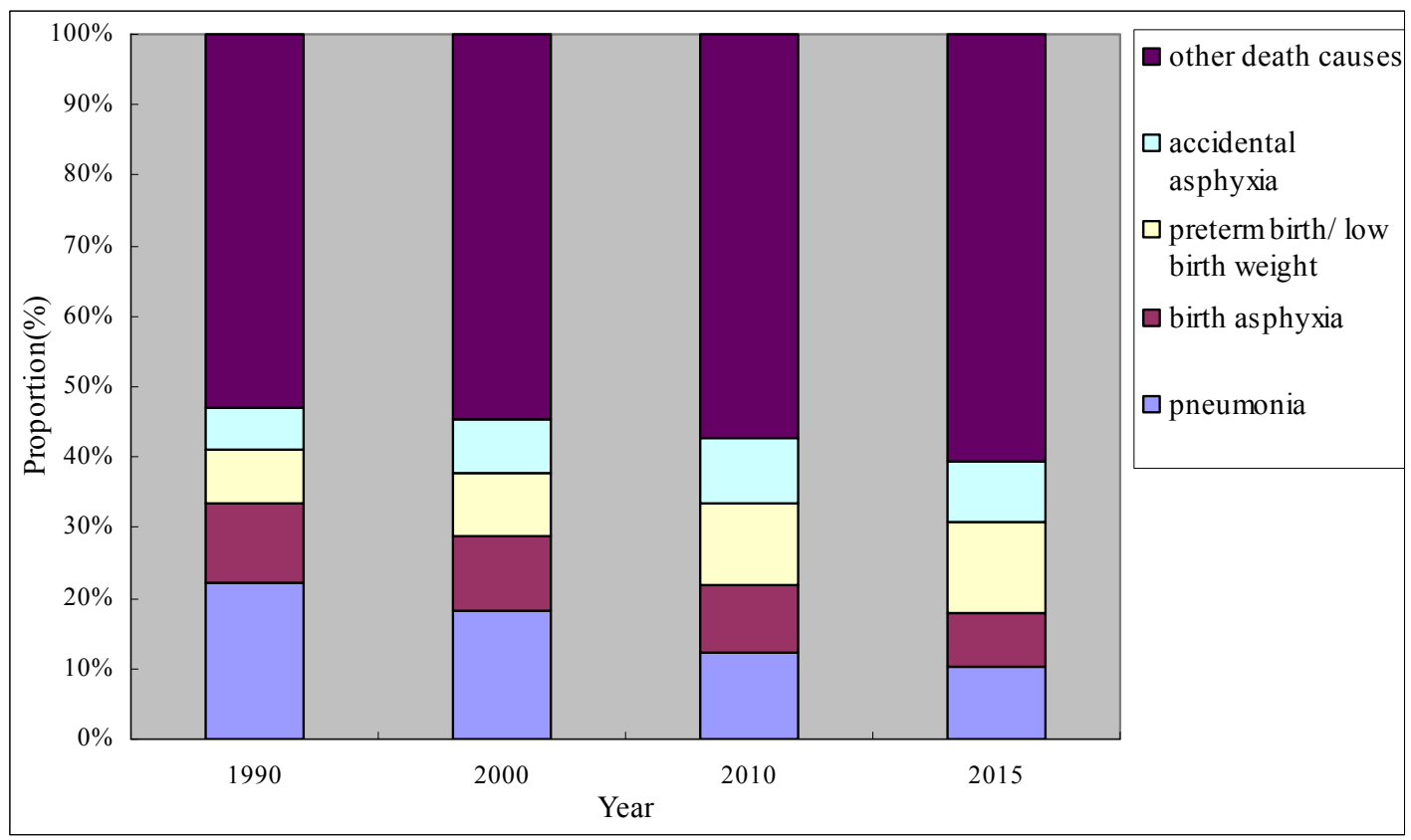

Figure 2. Proportions of the primary death causes for children under 5 years between 1990 and 2015 in Hubei Province of China (\%)

Primary death causes: pneumonia, birth asphyxia, preterm birth/low birth weight and accidental asphyxia. The other death causes were excluded from the causes listed above.

\subsection{Health Care Service}

The proportions of clinical diagnosis, emergence treatment and death place at the county/district hospitals increased from $9.0 \%, 27.4 \%$ and $28.7 \%$ in 1990 to $75.5 \%, 67.7 \%$ and $60.4 \%$ in 2015 respectively, and there were the significant differences between 1990 and 2015 in Hubei province $(\mathrm{P}<0.01)$ as shown in Table 1.

Table 1. Proportions of the health care service for children under 5 years between 1990 and 2015 in Hubei province of China

\begin{tabular}{|c|c|c|c|c|c|c|c|}
\hline \multirow{2}{*}{\multicolumn{2}{|c|}{ Health care service }} & \multicolumn{4}{|c|}{ Proportion (\%) } & \multirow{2}{*}{$\chi^{2 *}$} & \multirow{2}{*}{$\mathrm{P}$} \\
\hline & & 1990 & 2000 & 2010 & 2015 & & \\
\hline \multirow{4}{*}{$\begin{array}{l}\text { Clinical } \\
\text { Diagnosis }\end{array}$} & $\begin{array}{l}\text { In or above the county/district } \\
\text { hospitals }\end{array}$ & 9.0 & 30.3 & 61.3 & 75.5 & \multirow{4}{*}{50.18} & \multirow{4}{*}{$<0.01$} \\
\hline & At the town/street health centers & 31.3 & 26.2 & 14.5 & 6.3 & & \\
\hline & At the village health rooms & 32.6 & 21.3 & 7.7 & 4.2 & & \\
\hline & Without diagnosis & 27.1 & 22.2 & 16.5 & 14.0 & & \\
\hline \multirow{3}{*}{$\begin{array}{l}\text { Emergence } \\
\text { treatment }\end{array}$} & Inpatient treatment & 27.4 & 42.1 & 62.0 & 67.7 & \multirow{3}{*}{52.32} & \multirow{3}{*}{$<0.01$} \\
\hline & Outpatient treatment & 35.2 & 26.2 & 14.9 & 12.0 & & \\
\hline & Without treatment & 37.4 & 31.7 & 23.1 & 20.3 & & \\
\hline \multirow{3}{*}{ Death place } & $\begin{array}{l}\text { In or above the county/district } \\
\text { hospitals }\end{array}$ & 28.7 & 40.7 & 57.7 & 60.4 & \multirow{3}{*}{68.45} & \multirow{3}{*}{$<0.01$} \\
\hline & On the way to the hospitals & 11.2 & 8.6 & 11.9 & 9.9 & & \\
\hline & At home & 60.1 & 50.7 & 30.4 & 29.7 & & \\
\hline
\end{tabular}

* Chi-square test: significant differences between 1990 and 2015. 


\section{Discussion}

$\mathrm{U}_{5} \mathrm{MR}$ is interpreted as a measure of socioeconomic, environmental and cultural factors in a country or region (Walter et al., 2011). During the last two decades, child health has been steadily improving, though it still sustained a vast disparity in many countries. It was reported that $\mathrm{U}_{5} \mathrm{MR}$ in all the African countries was very high in the top ten countries, meanwhile those in all the European countries was very low in the last ten countries reported by several international organizations. This research manifested that $\mathrm{U}_{5} \mathrm{MR}$ in Hubei province was lower than those in all the developing countries which have represented the substantial progress across all the countries (Kenneth, Danzhen, Mie, \& Mikkel, 2012; Julie et al., 2010).

However, $\mathrm{U}_{5} \mathrm{MR}$ has a close correlation with the internal structure of the death causes for children under 5 years. Bourgeois recognized that the death causes were classified as the endogenous causes (for example birth asphyxia, preterm birth/low birth weight) and the exogenous causes (for example pneumonia) in accordance with the preventable degree of the mortality spectrum in children under 5 years. The endogenous causes were caused by some congenital malformations, genetic diseases or childbirth-related problems, while the exogenous causes were caused by some infections, malnutrition or unintentional injuries (Tatjana et al., 2013; Li et al., 2012; Khaled, 2000). The preventable mortality might be considerably controlled by a series of intervention measures of the national policies and health strategies for children under 5 years in China. This research showed that the mortality spectrum of the primary death causes manifested a distinguished milestone at which the mortality rates of pneumonia and birth asphyxia had been replaced by that of preterm birth/low birth weight after 2005 in Hubei province. Consequently, it was suggested that preterm birth/low birth weight was becoming the chief death cause for children under 5 years after the other death causes could be effectively controlled in Hubei province.

As mentioned above, it's worth nothing that preterm birth/low birth weight was becoming the primary death cause for children under 5 years in Hubei province, which was probably related with the high-aged puerperal, assisted reproductive technique, short reproductive interval and inferior pregnant health for fertile women (Brian et al., 2013; Rajvir \& Vrijesh, 2013; Betrán et al., 2007; Meredith, Laura, Joyce, Gary, \& Maurizio, 2003). Meanwhile, pneumonia and birth asphyxia had been gradually replaced by preterm birth/low birth weight in Hubei province, which were correlated with the acute respiratory infection management (ARI), expanded immunization program, effective asphyxia resuscitation and vigorous antibiotic treatment (Maurice et al., 2010; Wang et al., 2005). Therefore, the Chinese Government has been closely cooperated with some international organizations in pursuing several projects of health and wellbeing for children under 5 years. From now on, it should be an emphasis on our future work to reduce the mortality rates of preterm birth/low birth weight in Hubei province.

Historical studies of various political systems have revealed that governments were the most successful in promoting child health in many countries (Tariku \& Eshetu, 2013; Bamgboye, Cecilia, Adejuwonlo, \& Duro, 2012). As for the trends of the mortality spectrum, it was mainly due to the improvement of the health care service for children under 5 years in China, such as clinical diagnosis, emergence treatment and death place at the county/district hospitals. This research has indicated that the health care service for children under 5 years was significantly improved between 1990 and 2015 in Hubei province. Therefore, stronger health systems would effectively contribute to the national health progress towards reaching the target of MDG4 (Anna et al., 2012; Chandrakant \& Vinod, 2010).

\section{Conclusions}

The trends of the mortality spectrum were correlated with the improvement of the health care service for children under 5 years in Hubei province of China. In this research, pneumonia, birth asphyxia, preterm birth/low birth weight and accidental asphyxia were the major contributors to the mortality rates for children under 5 years over the past 25 years. There was a distinguished milestone of the mortality spectrum in which the major death causes have been transformed from pneumonia and birth asphyxia to preterm birth/low birth weight after 2005 . Moreover, the proportions of clinical diagnosis, emergence treatment and death place at the county/district hospitals were significantly improved from 1990 to 2015. Nevertheless, rapid reduction of the mortality rates and adjusted structure of the primary death causes would remain a health priority for children under 5 years in Hubei province.

\section{Contributors}

Zhonggui Xiong designed the preliminary methods, and analyzed the surveillance data in this research. Yusong $\mathrm{Xu}$ and Xiangdong Li critiqued the preliminary methods and results of this updated analysis. Junxin Shi reviewed the final version of the manuscript. All the authors contributed to the subsequent versions of the 
manuscript in this research.

\section{Conflicts of Interest}

We declared that we had no conflicts of interest in this research.

\section{Acknowledgements}

This research was supported by grants from Hubei Health and Family Planning Committee. The present research was conducted by a population-based surveillance network for children under 5 years in Hubei Province. We thanked all the child health professionals for their participation in the research over the past 25 years.

\section{References}

Anna, E. B., Linda, N. T., Kim-Huong, N., Sonja, F., Eliana, J.-S., \& Laura, D.-L. (2012). Equity and geography: the case of child mortality in Papua New Guinea. PLoS ONE, 7(5), e37861. https://doi.org/10.1371/journal.pone.0037861

Bamgboye, M. A., Cecilia, O. C., Adejuwonlo, E., \& Duro, D. (2012). A hospital-based estimate of major causes of death among under-five children from a health facility in Lagos, Southwest Nigeria: possible indicators of health inequality. Int $J$ for Equity in Health, 11, 39. https://doi.org/10.1186/1475-9276-11-39

Betrán, A. P., Merialdi, M., Lauer, J. A., Bing-Shun, W., Thomas, J., Van, L. P., \& Wagner, M. (2007). Rates of caesarean section: analysis of global, regional and national estimates. Paediatr Perinat Epidemiol, 21, 98-113. https://doi.org/10.1111/j.1365-3016.2007.00786.x

Brian, H., Alan, S., Kathleen, K., Sangeetha, M., Mark, C., Stephen, M. T. (2013). Household context and child mortality in rural South Africa: the effects of birth spacing, shared mortality, household composition and socioeconomic status. Int J Epidemiology, 1(11), 1444-1454. https://doi.org/10.1093/ije/dyt149

Chandrakant, L., \& Vinod, K. P. (2010). Burden, differentials, and causes of child deaths in India. Indian J Pediatr, 77, 1312-1321. https://doi.org/10.1007/s12098-010-0185-z

Julie, K. R., Linda, N. T., Alan, D. L., Christopher, JL M. (2010). Measuring under-five mortality: validation of new low-cost methods. PLoS Medicine, 7(4), e1000253. https://doi.org/10.1371/journal.pmed.1000253

Julie, K. R., Jake, R. M., Abraham, D. F., Haidong, W., Alison, L.-R., Laura, D. (2010). Neonatal, postneonatal, childhood, and under-5 mortality for 187 countries, 1970-2010: a systematic analysis of progress towards Millennium Development Goal 4. Lancet, 375, 1988-2008. https://doi.org/10.1016/S0140-6736(10)60703-9

Kenneth, H., Danzhen, Y., Mie, I., \& Mikkel, Z. O. (2012). Child mortality estimation: accelerated progress in reducing global child mortality, 1990-2010. PLoS Medicine, 9(8), e1001303. https://doi.org/10.1371/journal.pmed.1001303

Khaled, M. Y. (2000). Indices and sociodemographic determinants of childhood mortality in rural Upper Egypt. Social Science \& Medicine, 51, 185-197. https://doi.org/10.1016/S0277-9536(99)00459-1

Li, L., Hope, L. J., Simon, C., Jamie, P., Susana, S., Joy, E. L. (2012). Global, regional, and national causes of child mortality: an updated systematic analysis for 2010 with time trends since 2000. Lance, 379, 2151-2161. https://doi.org/10.1016/S0140-6736(12)60560-1

Maurice, O., Kubaje, A., Frank, O., Nabie, B., Rose, K., \& Laurence, S. (2010). Geospatial distribution and determinants of child mortality in rural western Kenya 2002-2005. Tropical Medicine \& International Health, 15(4), 423-433. doi:10.1111/j.1365-3156.2010.02467.x

Meredith, A. R., Laura, A. S., Joyce, A. M., Gary, J., \& Maurizio, M. (2003). Trends in multiple births conceived using assisted reproductive technology, United States, 1997-2000. Pediatrics, 111, 1159-1162

Rajvir, S., \& Vrijesh, T. (2013). Maternal factors contributing to under-five mortality at birth order 1 to 5 in India: a comprehensive multivariate study. Singh and Tripathi SpringerPlus, 2, 284. Retrieved from http://www.springerplus.com/content/2/1/284

Robert, E. B., Simon, C., Hope, L. J., Joy, E. L., Igor, R., \& Diego, G. B. (2010). Global, regional, and national causes of child mortality in 2008: a systematic analysis. Lancet, 375, 1969-1987. https://doi.org/10.1016/S0140-6736(10)60549-1

Tariku, D., \& Eshetu, G. (2013). Social determinants of under-five mortality in Ethiopia: Event history analysis using evidence from Ethiopian demographic and health survey (EDHS). Health, 5(5), 879-884. https://doi.org/10.4236/health.2013.55115 
Tatjana, G., Darija, K.-T., Jelena, D., Bojana, M., Anita, G., \& Tatjana, P. (2013). Patterns of infant mortality from 1993 to 2007 in Belgrade (Serbia). Matern Child Health, 17, 624-631. https://doi.org/10.1007/s10995-012-1039-2

Walter, M., Rosanna, C., Maurizio, M., Claudio, L. S., Giovanna, F., Salvatore, S. (2011). A retrospective follow up study on maternal age and infant mortality in two Sicilian districts. BMC Public Health, 11, 817. https://doi.org/10.1186/1471-2458-11-817

Wang, Y. P., Miao, L., Qian, Y. Q., Liang, J., Wu, Y. Q., Zhu, J., Dai, L., \& Zhou, G. X. (2005). Analysis of under 5 years old children mortality and the leading death cause in China from 1996 to 2000. Chin J preventive medicin, 39(4), 260-264

Wang, Y. P., Miao, L., Dai, L., Zhou, G. X., He, C. H., Li, X. H., Li, Q., \& Li, M. R. (2011). Mortality rate for children under 5 years of age in China from 1996 to 2006. Public Health, 125, 301-307. https://doi.org/10.1016/j.puhe.2011.01.003

You, D., Wardlaw, T., Salama, P., \& Jones, G. (2010). Levels and trends in under-5 mortality, 1990-2008. Lancet, 375, 100-103. https://doi.org/10.1016/S0140-6736(09)61601-9

\section{Copyrights}

Copyright for this article is retained by the author(s), with first publication rights granted to the journal.

This is an open-access article distributed under the terms and conditions of the Creative Commons Attribution license (http://creativecommons.org/licenses/by/4.0/). 